\title{
The thermal retrofitting of walls, windows and ceilings in traditional Scottish buildings
}

\author{
J. Stinson, J. Bros Williamson, A. Reid \& J. Currie \\ Scottish Energy Centre, Institute for Sustainable Construction, \\ Edinburgh Napier University, UK
}

\begin{abstract}
This paper documents research undertaken to evaluate the thermal transmittance of building elements - walls, windows and ceilings - both before and after the addition of insulation in traditionally constructed Scottish buildings. Thirteen different types of insulation (both natural and synthetic) were assessed during the study in a range of buildings.

The study found that in each instance where an insulation material was installed, regardless of location and method, an improved U-value of at least $38 \%$ was recorded, with a maximum improvement of $88 \%$. On average, solid wall insulation, either applied to the cavity, internal lining, or external face, reduced the U-value by $59 \%$, secondary glazing reduced the window U-value by $75 \%$, and ceiling insulation reduced the U-value by $77 \%$.

Keywords: conservation, preservation, historic building, retrofit, thermal performance.
\end{abstract}

\section{Introduction}

Traditionally-built residential properties (typically pre-1919) are, on average, less energy efficient and contribute more to $\mathrm{CO}_{2}$ emissions each year than any other age-defined categorisation of the housing stock in Scotland [1]. Of this pre-1919 category, $70 \%$ of homes in Scotland built with solid walls (no cavity) do not have any form of wall insulation whilst an additional $18 \%$ of this grouping also have no insulation on any external components $[1,2]$.

The remediation of traditional buildings - often characterised as 'hard-to-treat' - in terms of improving energy efficiency, is recognised as a significant and pressing challenge, both in meeting statutory carbon reduction targets and 
reducing instances of fuel poverty (UK households that spend more than $10 \%$ of their combined income on household fuel are consider to be in 'fuel poverty') [3] .

\section{Methodology}

The in-situ thermal conductance (U-value) $\left(\mathrm{W} / \mathrm{m}^{2} \mathrm{~K}\right)$ measurements were undertaken using the guidance as set out in ISO/DIS 9869-1:1994 Thermal insulation, building elements, In-situ measurement of thermal resistance and thermal transmittance - Part 1: Heat flow meter method, (now BS ISO 9869$1: 2014)$ [4]. This established methodology is endorsed by experienced academics [5-8].

The in-situ U-values were measured using the equipment presented in Figure 1. Thermopile-based heat flux transducers (Hukseflux HFP01) were used; these are $80 \mathrm{~mm}$ diameter and $5 \mathrm{~mm}$ thickness, providing a typical accuracy of $\pm 10 \%$. K-type thermocouples were attached to the face of the heat flux transducers and used to record internal temperatures. Transducers were connected to a Grant Squirrel data logger with 24 bit A-D conversion resolution. The transducers were attached internally to the surface of the respective wall, window and ceiling being evaluated. In each study, two transducers were co-located in order to ensure spatial averaging, and to provide mitigation against potential equipment failure. Gemini Tinytag View2 temperature loggers were used to record external temperature.

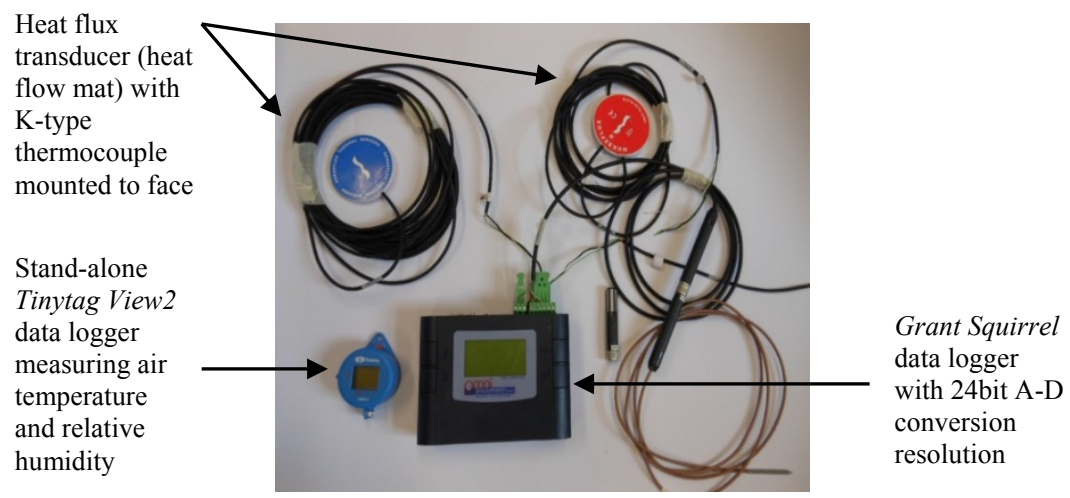

Figure 1: Testing equipment.

\subsection{Buildings characteristics and insulation materials}

The results presented in this paper were taken from thirteen properties located across Scotland, the age of the buildings range from mid- $18^{\text {th }}$ century to early $20^{\text {th }}$ century. Table 1 presents the characteristics of the pilot buildings and the number of examples in each grouping. All the properties involved in the study were typical examples of pre-1919 construction types in Scotland, including: solid stone external walls, with timber framed ceilings, pitched attic spaces and timber 
framed, single glazed sash and case windows. The majority of buildings in the study were domestic dwellings $(n=12)$, with 1 building in use as a library.

Many of the buildings were 'Listed' $(n=9)$ providing examples of the conservation legislation that needs to be considered when seeking to thermally enhance buildings with protected status. Historic Scotland provide the following definition of Listed buildings: "Listing is the recognition through the Planning (Listed Buildings and Conservation Areas) (Scotland) Act 1997 that a building or structure is of 'special' interest. Listing is used as a signal in the planning process that there is special interest which may need to be taken into account when changes are proposed" [9]. There were nine category B Listed buildings included in this study, meaning these buildings are of regional importance, or major examples of some particular period, style or building type. Approximately $50 \%$ of all listed buildings in Scotland are category B Listed.

Table 1: Number of pilot buildings sharing similar characteristics.

\begin{tabular}{|l|c|c|}
\hline \multicolumn{1}{|c|}{ Descriptor } & $\mathbf{n}$ & $\mathbf{\%}$ \\
\hline Location: East coast of Scotland & 10 & $77 \%$ \\
\hline Location: West coast, Scottish Island & 2 & $15 \%$ \\
\hline Location: Central Scotland & 1 & $8 \%$ \\
\hline Domestic dwelling & 12 & $92 \%$ \\
\hline Listed status & 9 & $69 \%$ \\
\hline Building type: Detached or terraced single or two storey building & 6 & $46 \%$ \\
\hline Building type: Flat in tenement building & 7 & $54 \%$ \\
\hline
\end{tabular}

Thirteen different insulation materials were selected and installed by Historic Scotland into the pilot buildings. Some of these buildings $(n=7)$ received multiple insulation treatments. Table 2 presents a list of the intervention types and their declared thermal conductivity $(\lambda)$ value $(\mathrm{W} / \mathrm{mK})$ as stated by ISO [10] or the installer specification sheet and the number of properties in which the insulation

Table 2: Number of different opaque insulations installed in the pilot buildings and the stated thermal conductivity of these materials.

\begin{tabular}{|l|c|c|}
\hline \multicolumn{1}{|c|}{ Opaque insulation } & $\mathbf{n}$ & $\boldsymbol{\lambda}(\mathbf{W} / \mathbf{m K})$ \\
\hline Aerogel blanket with plasterboard lining & 3 & 0.015 \\
\hline Cellulose fibre insulation & 3 & 0.038 \\
\hline Bonded expanded polystyrene bead & 5 & 0.038 \\
\hline Phenolic insulation with low-e foil cover & 5 & 0.020 \\
\hline Wood fibreboard & 2 & 0.040 \\
\hline Calcium silicate board & 1 & 0.070 \\
\hline Perlite & 1 & 0.040 \\
\hline Sheep's wool & 2 & 0.038 \\
\hline Flexible hemp batts & 1 & 0.040 \\
\hline
\end{tabular}


was installed (n). Four variations of secondary glazing were installed in four different properties, these included:

- Single pane transparent polycarbonate sheet;

- Single glazing with timber frame;

- Double glazing unit with aluminium frame;

- Double glazing unit with timber frame.

\subsection{The monitoring period}

All the properties were occupied and in normal use during both the pre and postintervention monitoring periods. Pre and post-intervention is used here to denote the period before and after the insulation was installed. All measurements were collected between winter 2010 and spring 2014. For both monitoring periods the apparatus recorded conditions between 14 and 21 days, installed between October and March. The pre and post-intervention measurements were taken 1 to 2 weeks before and after the installation were installed.

\subsection{Error analysis}

An error analysis was carried out on each of the pre and post-intervention measurements to add an 'uncertainty value' $( \pm \%)$ to the U-values data. The results were dependent on the temperature difference experienced at each monitored location. For testing at each location an internal/external temperature different of $>10^{\circ} \mathrm{C}$ was observed, the uncertainty of results ranged between \pm 4 and $\pm 10 \%$ for the pre and post-intervention values. On occasion where the temperature difference was greater than $>10$ the uncertainty value dropped. On average the uncertainty value calculated from these results was $\pm 10 \%$. It is recognised that an uncertainty level of $\pm 10 \%$ is common for this testing method $[6,8]$.

\section{Results}

The results of each intervention are considered in terms of building element in which they were tested - walls, windows, and ceilings. Due to the small number of samples for each intervention type, bar charts have been used to visualise the distribution of the U-value results and percentage improvement.

\subsection{Walls}

Traditionally constructed walls are generally built with solid stone $(400$ to $600 \mathrm{~mm}$ thick), either rubble or dressed in form with a rubble core, and bonded with lime mortar. Such walls are typically finished internally with a lath and plaster lining, maintaining a 30 to $50 \mathrm{~mm}$ air gap between the lining and stone wall.

Eight properties provided eighteen U-value measurements, with the findings presented in Figures 2 and 3. The pilot buildings provided examples of two natural stones common to Scotland - sandstone and whinstone. The average preintervention U-value for the sandstone walls $(\mathrm{n}=16)$ was $1.4 \mathrm{~W} / \mathrm{m}^{2} \mathrm{~K}$, and the 
average pre-intervention $U$-value for whinstone walls $(n=2)$ was $2.1 \mathrm{~W} / \mathrm{m}^{2} \mathrm{~K}$. Two variations of pre-intervention sandstone wall were measured, where the wall had a $30-50 \mathrm{~mm}$ cavity between the internal lining and stone $(\mathrm{n}=13)$ an average $U$-value of $1.3 \mathrm{~W} / \mathrm{m}^{2} \mathrm{~K}$ was obtained, in three instances where no air gap existed the Uvalue was on average $1.5 \mathrm{~W} / \mathrm{m}^{2} \mathrm{~K}$. It is common for solid walls with an air gap to have a lower U-value if the cavity is not externally ventilated.

Seven different wall insulation materials were installed. Below is a list of the 3 main installation techniques and the corresponding insulation material that was used.

1. An insulation blanket or board fixed to the face of the existing internal lining

- Aerogel blanket

2. Loose fill or blown insulation inserted into the gap between the lining and wall. This is an option where internal timber finishes, cornicing and window details must be retained, or where it would be difficult to apply material to the face of the lining. The $30-50 \mathrm{~mm}$ air gap is completely filled.

- Cellulose fibre insulation

- Bonded expanded polystyrene bead

- Perlite

3. The original lining removed and rigid insulation added around the framework, then new or original lining re-attached. Any air gap is now removed.

- Phenolic insulation with low-e foil cover

- Wood fibreboard

- Calcium silicate board

The results are shown in Figure 2, demonstrating that a significant U-value reduction can be attributed to each insulation material.

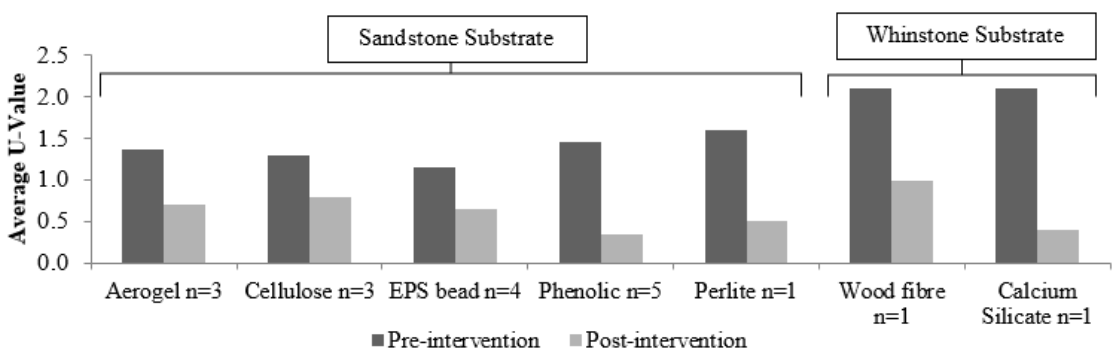

Figure 2: Average pre- and post-intervention U-values for each intervention type.

Figure 3 shows that in comparing the percentage improvements across the insulation types shows that the calcium silicate board insulation $(n=1)$ returned the largest improvement in post-intervention U-value (81\%). On average, the post- 
intervention U-value for the sandstone walls was $0.6 \mathrm{~W} / \mathrm{m}^{2} \mathrm{~K}$ - a $57 \%$ improvement. For the whinstone walls, the average post intervention U-value was $0.7 \mathrm{~W} / \mathrm{m}^{2} \mathrm{~K}-$ a $67 \%$ improvement.

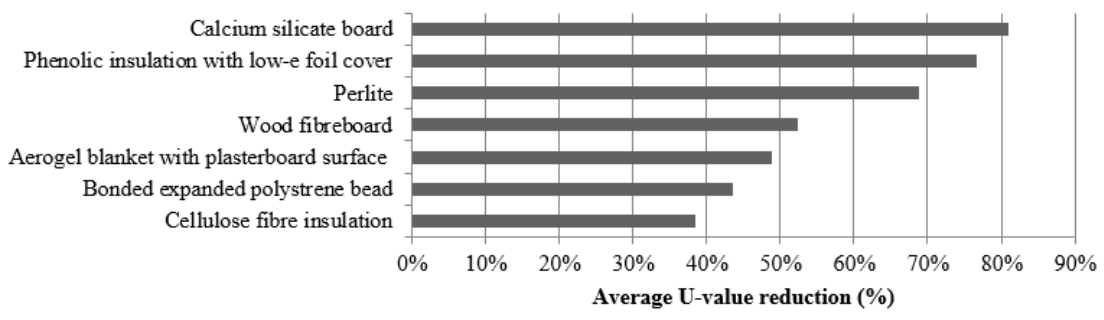

Figure 3: Average U-value reductions (\%) by intervention type.

\subsection{Windows}

Traditional timber sash and case windows typically make up a substantial proportion of the external surface area of traditional buildings in the UK and contribute significantly to heat loss. In measuring heat loss, the heat flux transducers were placed in the centre pane to measure the U-value. The pre and post-intervention U-value results are shown in Figure 4, again demonstrating significant $\mathrm{U}$-value reductions in each of the four interventions

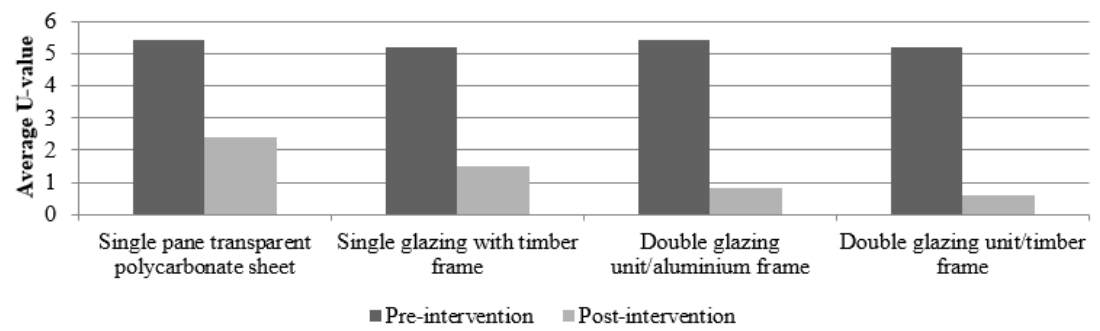

Figure 4: Average pre- and post-intervention U-values for each intervention type.

Figure 5 shows that the greatest reduction was observed in the intervention that involved installing a double glazed unit with a timber frame, providing an $88 \%$ reduction in the U-value. The least effective intervention was the single pane transparent polycarbonate sheet. However, this intervention still provided a $56 \%$ reduction. 


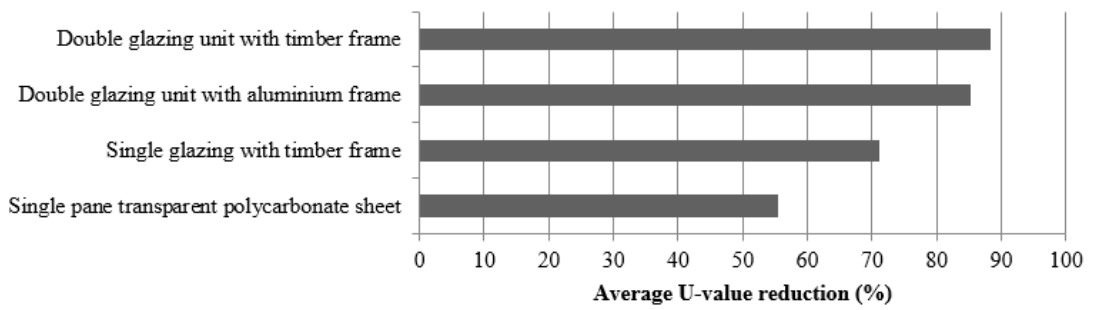

Figure 5: Average U-value reductions (\%) by intervention type.

\subsection{Ceilings}

Adding insulation to the ceiling has been shown to be an effective solution that can reduce the passage of heat and enhance the thermal performance of the ceiling. The selected insulations were applied between the ceiling joists; providing a simple, effective and relatively non-intrusive thermal solution. Care was taken to maintain ventilation in order to reduce the risk of moisture accumulation. Figure 6 shows the pre and post intervention U-value results, once again showing a significant reduction in each of the four interventions.

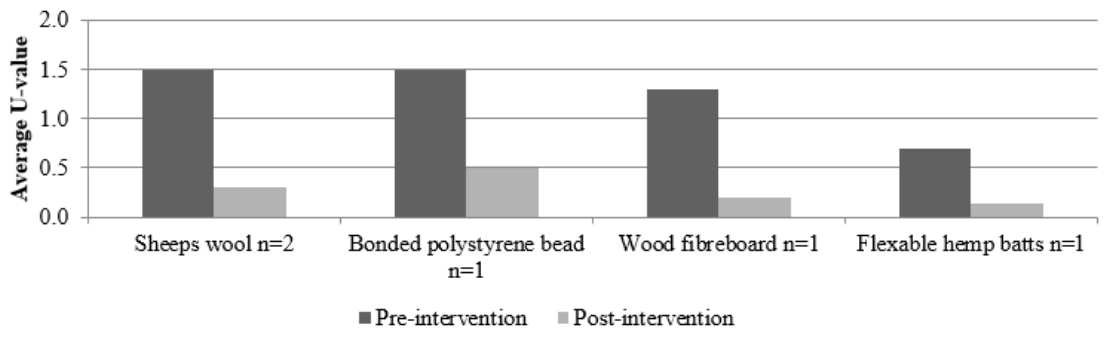

Figure 6: Average pre- and post-intervention U-values for each intervention type.

Figure 7 shows the U-value reductions (\%) attributed to each intervention type. The most effective insulation was found to be wood fibreboard, providing an $85 \%$ reduction in the U-value. An average post intervention improvement of $78 \%$ was measured from the 4 different insulation types. 


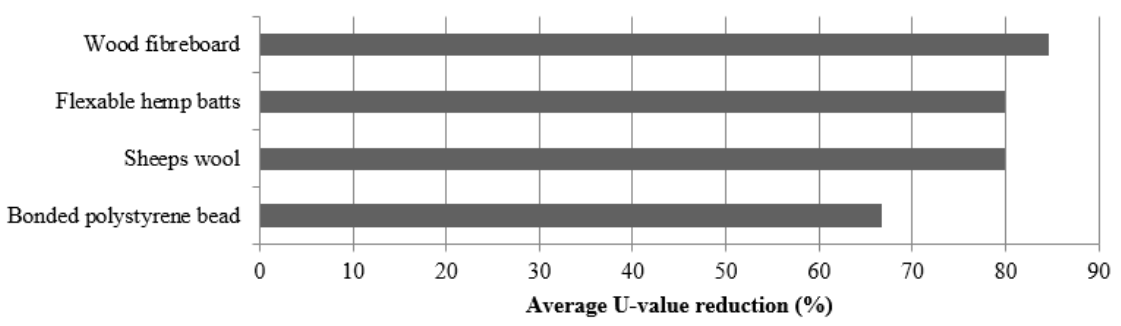

Figure 7: Average U-value reductions (\%) by intervention type.

\section{Conclusions}

This paper documents the results taken from thirteen traditional Scottish properties which were each monitored in order to assess the effectiveness of different insulation types in walls, windows, and ceilings. The results found that each intervention reduced the U-value significantly, ranging from a $38 \%-88 \%$ saving. Whilst the pilot buildings represent a collection of so-called 'hard to treat' properties in Scotland, the findings show that these buildings can be effectively insulated, including those with protected status. The uptake of such measures across the building stock has the potential to help reduce $\mathrm{CO}_{2}$ emissions and instances of fuel poverty.

\section{Acknowledgements}

The authors would like to thank the Historic Scotland Conservation Directorate and the National Trust for Scotland in providing access to the properties involved in this study.

\section{References}

[1] Scottish House Condition Survey 2013: Key Findings, The Scottish Government (2014) Available at: http://www.gov.scot/Resource /0046/00465627.pdf

[2] Low Carbon Behaviours Framework - Key Behaviour Areas - Data for Scotland, The Scottish Government, online. Available at: http://www.gov.scot/Publications/2013/10/3267/2

[3] The Scottish House Condition Survey: Fuel Poverty Evidence Review, 2012, The Scottish Government.

[4] ISO/DIS 9869-1:1994 Thermal insulation, Building elements, In-situ measurement of thermal resistance and thermal transmittance - Part 1: Heat flow meter method. London: BSI

[5] Baker, P., In situ U-value measurements in traditional buildings: Preliminary results. (Historic Scotland Technical Paper 2) [PDF] 
Edinburgh, 2008: Historic Scotland. Available at: www.historicscotland.gov.uk/uvalue_measurements_traditional_buildings.pdf

[6] Baker, P. Historic Scotland Technical paper 10: $\bar{U}$ - values and traditional buildings: in situ measurements and their comparisons to calculated values. 2011, Historic Scotland, online. Available at: www.historicscotland.gov.uk/hstp102011-u-values-and-traditional-buildings.pdf

[7] Rye, C., U-value report (SPAB Research Report; no.1). Revised ed. [PDF] London: SPAB, 2011. Available at: www.spab.org.uk/ downloads/The $\% 20$ SPAB $\% 20$ Research $\% 20$ Report $\% 201 . \% 20 U$-value $\% 20$ Report.\%20Revised\%20October\%202011.pdf

[8] Currie. J. Bros Williamson. J. \& Stinson. J. Historic Scotland Technical Paper 19: Monitoring Thermal Upgrades to Ten Traditional Properties, 2013, Historic Scotland, online. Available at: http://www.historicscotland.gov.uk/technicalpaper19.pdf

[9] What is listing? Historic Scotland, online Available at: http://www.historicscotland.gov.uk/index/heritage/historicandlistedbuildings/listing.htm

[10] BS EN ISO 10456: 2007, Building materials and products - Hygrothermal properties - Tabulated design values and procedures for determining declared and design thermal values. London: BSI 